\title{
Chinese Seniors' Leisure Participation and Constraints in Five Cities
}

\author{
Ying $\mathrm{Li}^{1}$, Baozhen $\mathrm{Luo}^{2}$, Chenchen Huang ${ }^{3} \&$ Junmin $\mathrm{Wu}^{4}$ \\ ${ }^{1}$ Department of Health \& Human Development, Western Washington University, Bellingham, WA, USA \\ ${ }^{2}$ Department of Sociology, Western Washington University, Bellingham, WA, USA \\ ${ }^{3}$ Hospitality and Tourism Department, State University of New York, Buffalo, NY, USA \\ ${ }^{4}$ Department of Social Security, School of Public Finance and Public Administration, Jiangxi University of \\ Finance and Economics, Nanchang, Jiangxi Province, P.R. China \\ Correspondence: Ying Li, Department of Health \& Human Development, Western Washington University, \\ Bellingham, WA, 98225, USA. Tel: 1-360-650-3513. E-mail: ying.li@wwu.edu
}

Received: August 7, 2017

doi:10.5539/ass.v13n11p24
Accepted: September 7, $2017 \quad$ Online Published: October 28, 2017

URL: https://doi.org/10.5539/ass.v13n11p24

\begin{abstract}
Leisure participation plays an important role in healthy aging. With the increasing elderly population and its potential social and economic influences, examining the factors that contribute to leisure constraints can be meaningful in evaluating and shaping Chinese seniors' leisure participation. Adopting a face-to-face cross-sectional design, this study interviewed 907 community-dwelling seniors in five cities across Eastern, Western, and Southeastern China to explore their leisure comprehension, participation, perceived constraints, and the relationship between demographic factors and perceived constraints. The results indicated that the participants were satisfied with their leisure participation in general; their leisure comprehension and participation were consistent with the literature. Various demographic factors influenced the perception of leisure constraints differently, with the city size of the participants' residence standing out in terms of its impact on the number of constraints. Recommendations for future research and policy development to promote healthy aging are discussed.
\end{abstract}

Keywords: leisure participation, leisure constraints, Chinese elderly, cross-sectional design

\section{Introduction}

China is becoming an aging society quickly at a rate that no other country in the world can match (China Power Team, 2016). How to help Chinese seniors to not just live longer, but - more importantly — to lead high-quality, productive, and independent lives has become even more important considering the tremendous social and economic impact of this increasing aging population. Leisure participation contributes to healthy aging (Gibson \& Singleton, 2012). To gain a better understanding of Chinese elderly leisure participation and constraints, the current study used a face-to-face cross-sectional design to interview 907 retirees from five cities across China.

\subsection{Leisure \& Aging}

It has been well established that spending time in leisure activities is positively associated with physical health, life satisfaction, and psychological wellbeing for the elderly (Gibson \& Singleton, 2012). Specifically, engaging in enjoyable and meaningful leisure activities can help in coping with stress and disabilities, decrease levels of depression and loneliness, reduce insomnia, improve the aging adjustment process, enhance social networking, prevent cognitive decline, and reduce the risk of dementia (Bennett, 2002; Dupuis, 2008; Endeshaw \& Yoo, 2016; Mannell \& Snelgrove, 2012; Scarmeas \& Stern, 2003; Wang, Karp, Winblad, \& Fratiglioni, 2002; Warr, Butcher, \& Robertson, 2004).

Although leisure plays a conceptually important role in people's lives, defining this concept is complicated (Kelly, 2012). Commonly, leisure is defined through time, activity, and experience (Hurd \& Anderson, 2011; Kelly, 2012). Specifically, leisure is: 1) time free from the necessity to labor for a livelihood, such as work and daily chores, 2) activities that free one from his or her obligations, and 3) experience that is positive and pleasant in its participants' view.

Elderly populations participate in different leisure activities, with sedentary activities as the primary form. Hogas and colleagues (1998) reported that the elderly spend about one-third of their waking hours watching television, 
reading, and doing other leisure activities. Among these activities, watching TV takes up more time than reading and participating in social activities (Hogas, Wilms, \& Baltes, 1998), which is consistent across different cultures. Specifically, a study conducted in Taiwan reported that the most common leisure activity for older Taiwanese adults aged 60 and over was watching TV/DVDs/videos, with more than $80 \%$ of the elderly doing so daily, while about half of older Taiwanese adults engaged daily in physical activities, $7 \%$ read books each day, and only $6.5 \%$ socialized with friends daily (Chen \& Fu, 2008). Although multiple studies reported that TV/DVD/video watching takes more time than other leisure activities, they did not necessarily indicate that the elderly enjoy this activity more. In fact, a nationally representative study reported that older Taiwanese adults most enjoyed socializing with friends, followed by engaging in physical activities, watching TV/DVDs/videos, and reading books (Chen \& Fu, 2008). Furthermore, Siegenthaler and Vaughan (1998) reported a group of older women living in retirement communities identified participating in physical activities as their favorite enjoyable pastime. They also enjoyed engaging in social activities and reading, among others, while watching TV was among their reported least interesting activities.

Various factors influence leisure participation among the elderly. Health status and age seem to consistently play a role in seniors' leisure engagement (Lefrancois, Leclerc, \& Poulin, 1998; Strain, Grabusic, Searle, \& Dunn, 2002). Specifically, an increase in age combined with poor health status decrease people's general leisure participation. The role of other demographic factors, such as place of residence or level of education, varies depending on the type of leisure activity. For example, rural senior adults appear more active in social visiting/chatting than older urban residents, while rural seniors are less likely to engage in physical leisure activities (Su, Shen, \& Wei, 2006).Education emerges as the most manifest predictor of leisure participation in reading books, but shows no effect on watching TV/DVDs/videos (Chen \& Fu, 2008).

\subsection{Leisure Constraints}

Leisure constraints refer to factors/reasons that "inhibit people's ability to participate in leisure activities, to spend more time doing so, to take advantage of leisure services or to achieve a desired level of satisfaction" (Jackson, 1988, p. 203), and evolved from the terms "recreation" and "barriers" from earlier studies (Dong \& Chick, 2012). A hierarchical leisure constraints model was first introduced by Crawford and Godbey (1987), and was later expanded by Crawford, Jackson, and Godbey in 1991, and then by Jackson, Crawford, and Godbey in 1993. These evolving models played an important role in understanding leisure behaviors and facilitated the development of a subfield in leisure study (Godbey, Crawford, \& Shen, 2010).

According to the hierarchical leisure constraints model, leisure constraints can be categorized into intrapersonal, interpersonal, and structural levels, and leisure participation is dependent upon the successful negotiation of these three levels in a sequential manner (Crawford, Jackson, \& Godbey, 1991; Jackson, Crawford, \& Godbey, 1993). Intrapersonal constraints refer to an individual's perception of his or herself that shapes the preference, interest, and motivation for leisure participation. An individual's assessment of competency, activity appropriateness, personal stress level, and attitude toward a specific activity are examples of this type of constraint. Interpersonal constraints result from interactions with others. Social support, social obligations, and companions are examples for this domain. Structural constraints involve external resources, such as the availability of the facility, transportation, and required participatory time.

Since its inception, the hierarchical leisure constraints model has received much attention and has served as the theoretical framework in numerous studies (Godbey, Crawford, \& Shen, 2010). To assess the status of this model and provide avenues for future research, Godbey and colleagues (2010) conducted a comprehensive literature review of research over the past two decades. According to Godbey and his colleagues (2010), "Another direction for integrative research in this field is to map the heterogeneity issue by exploring the effects of various relevant parameters (e.g., demographic/cultural background, types of activity, stages of participation, and so forth) as moderators in shaping perceptions of constraints..." (p. 127-128). At the same time, Godbey et al. (2010) also recommended that researchers focus on one single aspect due to the formidable nature of conducting an empirical study to capture all. Therefore, the current study focused only on examining the relationship between demographic background and the perception of constraints.

In addition, Dong and Chick (2012) stated that "research on leisure constraints in China is in its infancy. We believe that more descriptive research, as in several of the papers cited above, is sorely needed before launching into extensive hypothesis testing" (p. 421). With all of this in mind, the purpose of the current study was to explore 1) leisure comprehension, 2) leisure participation, 3) leisure constraints, and 4) how demographic factors affect the perception of leisure constraints among Chinese retirees. By addressing those aspects, we believe that the results of the study can add valuable information to the field. 


\section{Methods}

\subsection{Participants}

The participants were community-dwelling seniors in five cities-Hangzhou, Fuzhou, Nanchang, Leshan, and Suichang - across Eastern, Western, and Southeastern China.

\subsection{Procedure}

Human subject approval from the Institutional Review Board and informed consent by participants were obtained prior to data collection. An eight-page survey was distributed to 1,000 community-dwelling elders in China in five cities; in each city, 200 surveys were distributed. A quota sampling was used to capture the sex ratio of the elderly population in each city. Each survey was completed through face-to-face interviews by Chinese-speaking interviewers, who received training by the researchers to help them understand the research project, survey questions, human subject rights, and interview skills. In addition, ongoing consultation was provided whenever the interviewers had questions or needed support.

The participants were approached in their living communities and were provided with a small gift of appreciation, such as towels. Each survey question was read to the participant, and the answers were recorded by the interviewers and later entered into SPSS 16.0.

\subsection{Instrument}

The demographic section of the survey covered questions regarding participants' residence, age, gender, occupation before retirement, income, and marital status. Depending on the variable, the questions were either constructed in multiple-choice or fill-in-the-blank format.

The questions in the leisure section were adopted from the Taiwan 2007 ISSP (International Social Survey Programme): Leisure Time and Sports Questionnaire. The ISSP is a continuing annual program of cross-national collaboration with more than 50 nations on surveys covering topics deemed important for social science research. The questionnaire was originally drafted in English and then translated to Chinese using standard back translation procedures. Within the leisure section, the questions were further broken down into leisure comprehension, leisure participation, and perception of leisure constraints. To measure leisure comprehension and leisure constraint perception, participants were asked to rate statements using a five-point Likert scale ranging from strongly disagree (1) to strongly agree (5) and an option of "don't apply." For the reporting purpose, the opinions of "strongly agree" and "agree" were combined as "agree"; similarly, the opinions of "strongly disagree" and "disagree" were combined as "disagree." To understand their leisure participation, participants were given a list of leisure activities, such as watching TV, hiking, and gathering with friends, and asked to rate their participation frequency, again using a five-point Likert scale ranging from never (0) to daily (4).

\subsection{Data Analysis}

SPSS was used to produce descriptive statistics, such as the percentages for different leisure participation and educational background. Mplus was used for multiple linear regression to explore the relationship between demographic factors and the perception of leisure constraints because the dependent variables are categorical.

\section{Results}

\subsection{Demographic}

A total of 907 retirees participated in the study, with the majority being married ( $\mathrm{n}=691,78.3 \%$ ) and female $(\mathrm{n}=491,54.6 \%)$. Age-wise, each age category comprised roughly a third of the participants: 55-65 $(\mathrm{n}=310$, $34.2 \%)$, 66-75 $(n=342,37.7 \%)$, and 76-85 $(n=255,28.1 \%)$. Nearly one-third $(n=269,29.9 \%)$ had received elementary or lower education, $23.5 \%(\mathrm{n}=212)$ middle school education, $21.5 \%(\mathrm{n}=194)$ a high school diploma, and $25.1 \%(\mathrm{n}=226)$ college or higher education. In terms of their major income sources, $722(80.9 \%)$ of the participants had a retirement pension, with the rest receiving either governmental benefits/aid $(n=73,8.2 \%)$ or another income source $(\mathrm{n}=98,11 \%)$. Almost two thirds of the participants $(\mathrm{n}=543,59.9 \%)$ came from big cities (Hangzhou, Fuzhou, Nanchang - the capitals of the Zhejiang, Fujian, and Jiangxi provinces, respectively), and the others came from either a medium-sized city (Leshan) $(\mathrm{n}=176,19.4 \%)$ or a small city (Suichang) $(\mathrm{n}=188$, $20.7 \%)$. In terms of their health, half of the participants reported to have good $(\mathrm{n}=400,47.4 \%)$ or excellent $(\mathrm{n}=78$, $9.2 \%)$ health status, while others reported to be fair $(\mathrm{n}=278,32.9 \%)$, poor $(\mathrm{n}=76,9.0 \%)$, or very poor $(\mathrm{n}=12$, 1.4\%). (See Table 1.)

\subsection{Leisure Comprehension}

More than $80 \%$ of participants believed that leisure means "to relax myself" ( $\mathrm{n}=742,84.1 \%)$, "to do things that 
make myself happy" ( $n=738,83.1 \%)$, and "to do what I want to do" $(n=707,81.3 \%)$. About half of the participants believed that leisure means "to kill free time" ( $\mathrm{n}=460,53.4 \%)$ and "to do things without rewards" $(\mathrm{n}=383,44.5 \%)$. About one-third of the participants believed that leisure means "to do job-unrelated things" $(\mathrm{n}=292,33.9 \%)$. Less than $20 \%$ of participants $(\mathrm{n}=170,19.8 \%)$ believed that leisure means "to do nothing" $(\mathrm{n}=170,19.8 \%)$. Chi-square tests were used to explore the association between gender and leisure comprehension, but no statistical significance was identified.

\subsection{Leisure Participation}

The majority of participants $(\mathrm{n}=625,73.8 \%)$ were satisfied with their leisure participation $(137(16.2 \%)$ strongly agree, 488 (57.6\%) agree, $198(23.4 \%)$ neutral, 10 (1.2\%) disagree, 7 (0.8\%) strongly disagree, and $7(0.8 \%)$ does not apply). The most common leisure activity participants reported engaging in daily was Watching TV, DVD, or Video ( $\mathrm{n}=686,77.3 \%$ ), followed by Reading ( $\mathrm{n}=375,42.4 \%)$, Physical Activities $(\mathrm{n}=206,31.4 \%$ ), Listening to Music ( $n=161,18.4 \%)$, and Shopping with the Purpose of Leisure $(n=119,13.5 \%)$. The least common leisure activity retirees reported participating in daily was Watching Sports or Game in Stadium ( $\mathrm{n}=1$, $0.1 \%)$, followed by Engage in Arts ( $\mathrm{n}=9,1 \%)$, Family Member Gathering $(\mathrm{n}=21,2.4 \%)$, Crafting $(\mathrm{n}=29,3.3 \%)$, and Friends Gathering $(\mathrm{n}=36,4.1 \%)$.

\subsection{Leisure Constraints}

Among the six constraints, "health status" was identified by most participants ( $\mathrm{n}=624,66.0 \%)$ as the primary leisure constraint, followed by "availability of a companion" ( $\mathrm{n}=454,48.4 \%)$, "availability of facilities nearby" $(\mathrm{n}=417,44.6 \%)$, "amount of free time" ( $\mathrm{n}=495,42.8 \%)$, "the need of taking care of others" $(\mathrm{n}=333,35.7 \%)$, and "income" ( $\mathrm{n}=260,28.2 \%)$.

Multiple linear regression analysis (Mplus) was used to identify the demographic factors that may play a role for each leisure constraint. The results of the regression indicated that the demographic factors affect the constraints differently. It was found that "income source," "occupation before retirement," "city size of residence," and "self-perceived health status" mattered when "health status" became a constraint for participants $\left(\mathrm{R}^{2}=.066\right)$. Specifically, people who rely on social welfare were more likely to identify "health status" as a constraint compared to people who had a pension $(\beta=.516, p=.006)$; people who used to be farmers $(\beta=-.644, p=.001)$ or had other career choices $(\beta=-.526, p=.011)$ were less likely to identify "health status" as a constraint; medium-sized city retirees were less likely to identify "health status" as a constraint than people from big cities ( $\beta=-.301, p=.013$ ) (but there were no significant differences between small and big cities); and retirees with better "self-perceived health status" were less likely to identify "health status" as a determinant $(\beta=-.140$, $p=.010)$.

Specific demographic factors became significant predictors for the constraints of "availability of a companion" $\left(\mathrm{R}^{2}=.053\right)$ and "amount of free time" $\left(\mathrm{R}^{2}=.056\right)$. Specifically, medium-sized city retirees were less likely to identify "availability of a companion" as a constraint than those from big cities $(\beta=-.339, p=.004)$, but there was no significant difference between small- and big-city retirees. The older the retiree, the less likely he or she identified "amount of free time" as a constraint $(\beta=-.022, p=.000)$.

The results suggested that "occupation before retirement" and "city size of the residence" significantly predicted if "availability of facilities nearby" became a constraint for participants $\left(\mathrm{R}^{2}=.109\right)$. Retirees who used to be farmers $(\beta=-.408, p=.031)$ or had other occupation choices $(\beta=-.672, p=.000)$ were less likely to identify "availability of facilities nearby" as a constraint; small-city retirees were less likely to identify "availability of facilities nearby" as a constraint in contrast to big-city retirees $(\beta=-.483, p=.000)$, but there were no significant differences between those from medium-sized and big cities.

Additionally, the results suggested that "marital status" and "city size" significantly predicted if "the need of taking care of others" became a constraint for participants $\left(\mathrm{R}^{2}=.086\right)$. Retirees who were married were more likely to identify "the need of taking care of others" as a constraint than those of another marital status $(\beta=.266$, $p=.016)$. Furthermore, small-city $(\beta=-.318, p=.004)$ and medium-sized city $(\beta=-.546, p=.000)$ retirees were less likely to identify "the need of taking care of others" as a constraint than retirees from big cities.

For the constraint of "income" $\left(\mathrm{R}^{2}=.071\right)$, the demographic factors of "age," "education level," "occupation before retirement," and "city size" became significant predictors. Specifically, people who used to be farmers $(\beta$ $=-.409, p=.030$ ) were less likely to identify "income" as a constraint compared to those who opted for all other career choices; medium-sized city retirees were less likely to identify "income" as a constraint than retirees from big cities $(\beta=-.256, p=.015)$, but there was no significant difference between small and big cities. The older the participant, the less likely "income" was identified as a constraint $(\beta=-.017, p=.005)$. In addition, retirees with 
"a high school diploma" ( $\beta=-.264, p=.048)$ and "college or higher degree" $(\beta=-.529, p=.000)$ were less likely to identify "income" as a constraint compared to people who received just elementary or middle school education.

\section{Discussion}

The results indicated that the concept of leisure is individual dependent, multi-dimensional, and complex, which concurs with the literature (Kelly, 2012). In addition, the results also pointed to the importance of the aspects of relaxation, joy, and freedom of choice that leisure brings to people's lives, as more than $80 \%$ of participants agreed with the leisure definitions of "relaxing myself," "engaging in activities that make myself happy," and "doing what I want to do." It is also interesting that only $20.7 \%$ of the participants believed that "leisure means doing nothing," as the traditional ideal retirement lifestyle in Chinese culture is "Xiang qin fu," which literally means enjoying the fortune of doing nothing (Thang, 2005). This incongruity may be explained by the social and economic changes occurring in China, as well as by the government's efforts to promote healthy aging. Specifically, the Chinese government has issued more than 200 laws, policies, and regulations regarding Chinese seniors' health, education, entertainment, and rights over the past 20 years (State Council of the People's Republic of China, 2006). One example is the Starlight Project launched by China's Ministry of Civil Affairs in 2001, which aimed to build physical infrastructures to host a variety of community-based service programs such as health and wellness clinics, recreational activities, and home visits (Leung \& Wong, 2002). According to the State Council of the People's Republic of China (2006), this program helped to set up 32,000 "Starlight Centers for Seniors," benefiting more than 30 million elderly people.

Watching TV/DVDs/videos was the most popular leisure activity for participants, which is consistent with the findings from other studies (Chen \& Fu, 2008). It is understandable that Watching Sports or Game in Stadium was the least popular leisure activity, as those types of activities are not popular in China to start with. Importantly, most participants reported satisfaction with their leisure experience, which may be explained by the governmental efforts mentioned above.

According to the hierarchical leisure constraints model, "health status" belongs to the intrapersonal constraint - the first level of the sequential negotiation process for leisure participation (Crawford, Jackson, \& Godbey, 1991; Jackson, Crawford, \& Godbey, 1993) — which explains why "health status" was identified as the primary constraint by the highest percentage of the participants. At the same time, identifying "health status" as one of the leisure constraints is consistent with the literature, as numerous studies have confirmed the importance of health status in leisure participation among the elderly. Less than half of the participants reported perceived constraints for the other choices listed in the survey, such as the interpersonal constraint of "availability of a companion" and the structural constraint of "availability of facilities nearby," which partially supports this theory but necessitates further exploration.

The results of the current study indicate that demographic factors - education, income source, occupation before retirement, age, gender, city size of the residence, marital status, and self-perceived health status - affect the perception of leisure constraints differently. Among all the demographic factors, "city size of the residence" demonstrated its considerable impact across all leisure constraints ("health status," "availability of a companion," "availability of facilities nearby," "the need to take care of others," and "income") except "the amount of free time I have." Compared to their counterparts living in big cities, the elderly living in medium- and small-sized cities were less likely to report these constraints, which may be partially explained by the characteristics associated with big cities throughout the growing urbanization of China.

Urbanization in China has been unique and rapid, which has played an important role in its economic development (National Bureau of Statistics of China, 2010). However, this unprecedented urbanization also introduced many issues - such as transportation congestion, pollution (Zhao, 2010), and inequality of resources for migrants - that affect the quality of life for local residents (Gong et al., 2012; Li et al., 2016). This new reality may explain why the participants from small cities were less likely than their counterparts from big cities to report "availability of facilities nearby" as a leisure constraint, because big cities have more resources in total but not necessarily per person. In addition, the traffic congestion in big cities may make "availability of facilities nearby" less reachable.

The commuting inconvenience associated with big cities may also explain the reason why the participants from both medium-sized and small cities were less likely to report the leisure constraint of "the need to take care of others," as the traffic makes the need to commute to different locations in order to take care of others even more burdensome in a larger city. Along the same lines, traffic-related inconvenience makes support from one's social network or kinship less feasible, which can make the participants who bear the responsibility of taking care of 
others less likely to have time for themselves.

It is interesting that the participants living in medium-sized but not small cities were less likely to report "availability of a companion," "health status," and "income" as leisure constraints in comparison to the participants from big cities. This may be explained by the balance between the positive and negative effects associated with urbanization, or the scale of urbanization. As mentioned above, urbanization is a double-edged sword - create opportunity and convenience in certain aspects while introducing problems at the same time, such as transportation congestion, air pollution, and resource inequality. When urbanization occurs, it may initially encourage leisure participation and decrease leisure constraints, but the positive effects decrease over time to the point where the negative effects outweigh the positive ones. In other words, the relationship between the leisure constraint perception and urbanization is nonlinear. Unfortunately, developing and testing a model to establish the relationship between urbanization and leisure constraint perception is beyond the scope of the current study, but this points to a direction for future research.

The next demographic factor that played a significant role in multiple perceived leisure constraints was career choice before retirement. Specifically, participants who used to be farmers were less likely to report "health status," "availability of facilities nearby," and "income" as perceived leisure constraints in comparison to participants who used to work in governmental agencies. Su and colleagues (2006) studied participation in different leisure activities between rural and urban elderly in China. They reported that $60 \%$ of rural elderly selected "taking care of grandchildren" and "housework" as their daily leisure activities, while $68.9 \%$ of urban elderly selected "attending senior school" and "recreation (playing card/board games, physical exercise, shopping, etc.)" as their daily leisure activities. Understandably, "taking care of grandchildren" and "housework" do not require a facility, whereas "attending senior school" and "recreation" demand a facility. The difference in the leisure activity choice and consequently its requirement may explain why people who used to be farmers tend to live in rural areas and are less likely to view "availability of facilities nearby" as a constraint. Su and colleagues (2006) also reported the difference in preference for leisure activities between urban and rural elderly. Specifically, $33.1 \%$ of urban elderly residents selected "traveling" as their favorite activity, compared to $15.1 \%$ of rural elderly residents. At the same time, $30.3 \%$ of rural elderly viewed "playing with kids" as their favorite activity. Generally speaking, traveling requires more financial resources than playing with kids, which may suggest that income is not perceived as a constraint for retirees who used to be farmers because their leisure activities require less financial resources, and in turn their choices make income less of a constraint. This is consistent with the findings from Kay and Jackson's study (1991) about the impact of leisure constraints on leisure participation. The results of their study suggested that the types of leisure activities in which people engage play a role in their perception of leisure constraints.

The results of the current study indicated that the older the participants, the less likely they were to report "amount of free time" and "income" as leisure constraints. There are a few reasons that may help to explain this finding. First, Chinese elderly usually help take care of grandchildren when they are too young to go to daycare (Ko \& Hank, 2014). When grandchildren grow and begin daycare or school, the elderly have aged even more and have the opportunity for more free time for themselves. Second, at the certain age point when health status may start to restrict the activities the elderly can do, they may be faced with extra time to fill; at the same time, this activity restriction may also spare the elderly the financial resources required to engage in activities that are expensive, such as traveling. Third, Confucianism expects adult children to help take care of the elderly, including providing financial assistance (Fan, 2007); thus, income becomes less of a leisure constraint. With aging elderly having more free time and less concerns over financial resources, it is important to guide them to participate in leisure activities that are appropriate for them.

\section{Conclusion}

In summary, with the government's support, overall leisure participation among Chinese elderly is positive. However, leisure constraints continue to exist. Demographic factors impact the leisure constraint perception differently. The city size of the residence, career choice before retirement, and age seem more critical in comparison to other demographic factors in contributing to the leisure constraints examined in the current study. At the same time, the type of leisure activity in which people engage also contributes to the leisure constraint perception. To help Chinese elderly enjoy their retirement life, the Chinese government should continue its efforts and investment in supporting their participation in leisure activities. Specifically, the central government should take an active role in helping local governments in urban planning to maximize the benefits and minimize the negative consequences of urbanization on residents' lives. China released the New-type Urbanization Plan (2014-2020) in 2014 as an effort to steer the country onto a more human-centered and environmentally friendly path to urbanization, which should be applauded (Wang, Hui, Choguill, \& Jia, 2015). In addition, the Chinese 
government should also incorporate the action plan stipulated by the World Health Organization in promoting an aging-friendly environment (WHO, 2016).

More empirical study should be conducted to understand the relationship between urbanization and leisure participation, which may provide a direction for improved city planning. Last, more efforts may need to be put into the older elderly — who tend to have more free time and less concerns regarding income - to help them find healthy and meaningful leisure activities.

Any interpretation of the results from the current study should take into consideration the following limitations. First, the sample obtained was a convenience sample, which may limit its generalizability. However, the data was collected from five cities across three different regions, which may alleviate some of those issues. Second, all information was self-reported and was therefore subject to social desirability response bias. However, the emphasis on anonymity at the beginning of the survey encouraged honest answers.

\section{References}

Bennett, K. M. (2002). Low level social engagement as a precursor of mortality among people in later life. Age Ageing, 31(3), 165-168. https://doi.org/10.1093/ageing/31.3.165

Chen, S., \& Fu, Y. (2008). Leisure participation and enjoyment among the elderly: Individual characteristics and sociability. Educational Gerontology, 34(10), 871-889. https://doi.org/10.1080/03601270802115382

China Power Team. (2016). Does China have an aging problem? China Power. Accessed August 6, 2017. http://chinapower.csis.org/aging-problem/

Crawford, D. W., \& Godbey, G. (1987). Reconceptualizing barriers to family leisure. Leisure Sciences, 9(2), 119-127.

Crawford, D. W., Jackson, E. L., \& Godbey, G. (1991). A hierarchical model of leisure constraints. Leisure Sciences, 13(4), 309-320.

Dong, E., \& Chick, G. (2012). Leisure constraints in six Chinese cities. Leisure Sciences, 34(5), 417-435. https://doi.org/10.1080/01490400.2012.714702

Dupuis, S. L. (2008). Leisure and ageing well. World Leisure Journal, 50(2), 91-107.

Endeshaw, Y. W., \& Yoo, W. (2016). Association between social and physical activities and insomnia symptoms among community-dwelling older adults. Journal of Aging and Health, 28(6), 1073-1089. https://doi.org/10.1177/0898264315618921

Fan, R. (2007). Which care? Whose responsibility? And why family? A Confucian account of long-term care for the elderly. The Journal of Medicine and Philosophy, 32(5), 495-517.

Godbey, G., Crawford, D. W., \& Shen, X. S. (2010). Assessing hierarchical constraints theory after two decades. Journal of Leisure Research, 42(1), 111-134.

Gibson, H., \& Singleton, J. (2012). Leisure \& aging: Theory \& practice (2nd ed.). Champaign: Human Kinetics.

Gong, P., Liang, S., Carlton, E. J., Jiang, Q., Wu, J., Wang, L., \& Remais, J. V. (2012). Urbanization and health in China. Lancet, 379(9818), 843-852. https://doi.org/10.1016/S0140-6736(11)61878-3

Hogas, A. L., Wilms, H. U., \& Baltes, M. M. (1998). Daily life in very old age: Everyday activities as an expression of successful living. The Gerontologist, 38(5), 556-568.

Hurd, A. H., \& Anderson, D. M. (2011). Park and recreation professional's handbook with online resource. Champaign, IL: Human Kinetics.

International Social Survey Programme. (2007). Leisure time and sports. Retrieved from http://zacat.gesis.org/webview/index.jsp?object=http://zacat.gesis.org/obj/fStudy/ZA4850

Jackson, E. L. (1988). Leisure constraints: A survey of past research. Leisure Sciences, 10(3), 203-215.

Jackson, E. L., Crawford, D. W., \& Godbey, G. (1991). Negotiation of leisure constraints. Leisure Sciences, $15(1), 1-11$.

Kay, T., \& Jackson, G. (1991). Leisure despite constraints: The impact of leisure constraints on leisure participation. Journal of Leisure Research, 23(4), 301-313.

Kelly, J. (2012). Leisure. Urbana, IL: Sagamore Publishing.

Ko, P. C., \& Hank, K. (2014). Grandparents caring for grandchildren in China and Korea: Findings from CHARLS and KLoSA. Journals of Gerontology, Series B: Psychological Sciences and Social Sciences, 
69(4), 646-651. https://doi.org/10.1093/geronb/gbt129

Lefrancois, R., Leclerc, G., \& Poulin, N. (1998). Predictors of activity involvement among older adults. Activities, Adaptation \& Aging, 22(4), 15-29.

Leung, J. C. B., \& Wong, Y. C. (2002). Community-based services for frail elderly in China. International Social Work, 45(2), 205-216.

Li, X., Song, J., Lin, T., Dixon, J., Zhang, G., \& Ye, H. (2016). Urbanization and health in China, thinking at the national, local and individual levels. Environmental Health, 15(Suppl. 1)(32), 113-123. https://doi.org/10.1186/s12940-016-0104-5

Mannell, R., \& Snelgrove, R. (2012). Leisure and the psychological well-being and health of older adults. In H. Gibson, \& J. Singleton (Eds.), Leisure and aging: Theory and practice (pp. 143-154). Champaign, IL: Human Kinetics.

National Bureau of Statistics of China. (2010). National statistics yearbook (in Chinese). Beijing: China.

Scarmeas, N., \& Stern, Y. (2003). Cognitive reserve and lifestyle. Journal of Clinical and Experimental Neuropsychology, 25(5), 625-633. https://doi.org/10.1076/jcen.25.5.625.14576

Siegenthaler, K. L., \& Vaughan, J. (1998). Older women in retirement communities: Perceptions of recreation and leisure. Leisure Sciences, 20(1), 53-66.

State Council of the People's Republic of China. (2006). The development of the China's Undertakings of the Aged. Retrieved from http://www.gov.cn/english/2006-12/12/content_467341_5.htm.

Strain, L. A., Grabusic, C. C., Searle, M. S., \& Dunn, N. J. (2002). Continuing and ceasing leisure activities in later life: A longitudinal study. The Gerontologist, 42(2), 217-223. https://doi.org/10.1093/geront/42.2.217

$\mathrm{Su}$, B., Shen, X., \& Wei, Z. (2006). Leisure life in later years: Differences between rural and urban elderly residents in China. Journal of Leisure Research, 38(3), 381-397.

Thang, L. (2005). Experiencing leisure in later life: A study of retirees and activity in Singapore. Journal of Cross Culture Gerontology, 20(4), 307-318. https://doi.org/10.1007/s10823-006-9010-6

Wang, H. X., Karp, A., Winblad, B., \& Fratiglioni, L. (2002). Late-life engagement in social and leisure activities is associated with a decreased risk of dementia: A longitudinal study from the Kungsholmen project. American Journal of Epidemiology, 155(12), 1081-1087. https://doi.org/10.1093/aje/155.12.1081

Wang, X., Hui, E. C., Choguill, C., \& Jia, S. (2015). The new urbanization policy in China: Which way forward? Habitat International, 47, 279-284. https://doi.org/10.1016/j.habitatint.2015.02.001

Warr, P., Butcher, V., \& Robertson, I. (2004). Activity and psychological well-being in older people. Aging \& Mental Health, 8(2), 172-183. https://doi.org/10.1080/13607860410001649662

World Health Organization. (2016). Multisectoral action for a life course approach to healthy ageing: Draft global strategy and plan of action on ageing and health. Retrieved from http://apps.who.int/gb/ebwha/pdf_files/WHA69/A69_17-en.pdf?ua=1

Zhao, P. (2010). Sustainable urban expansion and transportation in a growing megacity: Consequences of urban sprawl for mobility on the urban fringe of Beijing. Habitat International, 34(2), $236-243$. https://doi.org/10.1016/j.habitatint.2009.09.008

Table 1. Demographic Distribution among Participants

\begin{tabular}{cccc}
\hline & Demographic variables & $\mathrm{n}$ & $\%$ \\
\hline \multirow{2}{*}{ Age } & $55-65$ & 310 & $34.2 \%$ \\
& $66-75$ & 342 & $37.7 \%$ \\
& $76-85$ & 255 & $28.1 \%$ \\
\hline \multirow{3}{*}{ Education } & Elementary or lower & 269 & $29.9 \%$ \\
& Middle school & 212 & $23.5 \%$ \\
& High school & 194 & $21.5 \%$ \\
\hline \multirow{2}{*}{ Gender } & College or above & 226 & $25.1 \%$ \\
\hline \multirow{2}{*}{} & Female & 491 & $54.6 \%$ \\
\end{tabular}




\begin{tabular}{cccc}
\hline \multirow{3}{*}{ Health } & Very poor & 12 & $1.4 \%$ \\
& Poor & 76 & $9.0 \%$ \\
& Fair & 278 & $32.9 \%$ \\
& Good & 400 & $47.4 \%$ \\
& Excellent & 78 & $9.2 \%$ \\
\hline \multirow{2}{*}{ Income } & Retirement pension & 722 & $80.9 \%$ \\
& Government aid & 73 & $8.2 \%$ \\
\hline \multirow{2}{*}{ Marital status } & Others & 98 & $11.0 \%$ \\
\hline \multirow{2}{*}{ Residency } & Married & 691 & $78.3 \%$ \\
& Single/widowed/separated & 191 & $29.1 \%$ \\
\hline & Small city & 188 & $20.7 \%$ \\
\end{tabular}

Table 2. Leisure Comprehension

\begin{tabular}{|c|c|c|c|c|}
\hline I believe that leisure means ... & $\begin{array}{l}\text { Agree } \\
\mathrm{n}(\%)\end{array}$ & $\begin{array}{c}\text { Neutral } \\
\text { n }(\%)\end{array}$ & $\begin{array}{c}\text { Disagree } \\
\mathrm{n}(\%)\end{array}$ & $\begin{array}{c}\text { Don't Apply } \\
\text { n (\%) }\end{array}$ \\
\hline Relaxing myself & $742(84.1)$ & $131(14.9)$ & $6(0.7)$ & $3(0.3)$ \\
\hline Engaging in activities that make myself happy & $738(83.1)$ & $133(15.0)$ & $13(1.4)$ & $4(0.5)$ \\
\hline Doing what I want to do & $707(81.3)$ & $132(15.2)$ & $23(2.6)$ & $8(0.9)$ \\
\hline Killing free time & $613(53.4)$ & $235(27.3)$ & $146(16.9)$ & $20(2.4)$ \\
\hline Engaging in activities without any rewards & $415(44.6)$ & $376(40.4)$ & $113(12.2)$ & $26(2.8)$ \\
\hline Engaging in activities that are job-unrelated & $320(34.4)$ & $316(34.0)$ & $262(28.0)$ & $34(3.7)$ \\
\hline Doing nothing & $192(20.7)$ & $300(32.3)$ & $414(44.7)$ & $22(2.4)$ \\
\hline
\end{tabular}

Table 3. Leisure Participation Determinants

\begin{tabular}{|c|c|c|c|c|}
\hline $\begin{array}{l}\text { My leisure activity engagement is primarily determined } \\
\text { by ... }\end{array}$ & $\begin{array}{l}\text { Agree } \\
\mathrm{n}(\%)\end{array}$ & $\begin{array}{c}\text { Neutral } \\
\mathrm{n}(\%)\end{array}$ & $\begin{array}{c}\text { Disagree } \\
\mathrm{n}(\%)\end{array}$ & $\begin{array}{c}\text { Don't Apply } \\
\text { n }(\%)\end{array}$ \\
\hline My health status & $624(66.0)$ & $186(19.7)$ & $121(12.8)$ & $15(1.6)$ \\
\hline The availability of a companion & $454(48.4)$ & $242(25.8)$ & $219(23.3)$ & $23(2.5)$ \\
\hline The availability of facilities nearby & $417(44.6)$ & $228(24.4)$ & $265(28.3)$ & $25(2.7)$ \\
\hline The amount of free time I have & $495(42.8)$ & $218(23.2)$ & $210(22.4)$ & $15(1.6)$ \\
\hline The need of taking care of others & $333(35.7)$ & $270(28.9)$ & $299(32.0)$ & $31(3.3)$ \\
\hline My income & $260(28.2)$ & $260(28.2)$ & $381(41.3)$ & $21(2.3)$ \\
\hline
\end{tabular}

Table 4. Predictors for Leisure Participation Determinants

\begin{tabular}{|c|c|c|c|}
\hline Predicators & $S E$ & $\beta$ & $p$ \\
\hline \multicolumn{4}{|l|}{ Determinant: Health Status } \\
\hline Income with social welfare & .187 & .516 & .006 \\
\hline Career choice: farmer & .198 & -.644 & .001 \\
\hline Career choice: others & .208 & -.526 & .011 \\
\hline City size: medium & .122 & -.301 & .013 \\
\hline Health & .054 & -.140 & .010 \\
\hline \multicolumn{4}{|l|}{ Determinant: Companion } \\
\hline City size: medium & .117 & -.339 & .004 \\
\hline \multicolumn{4}{|l|}{ Determinant: Facilities } \\
\hline Career choice: farmer & .189 & -.408 & .031 \\
\hline Career choice: others & .172 & -.672 & .000 \\
\hline City size: small & .107 & -.483 & .000 \\
\hline \multicolumn{4}{|l|}{ Determinant: Free time } \\
\hline Age & .006 & -.022 & .000 \\
\hline
\end{tabular}


Determinant: Take care of others

City size: medium

City size: small

Marital status

Determinant: Income

Age

Career choice: farmer

City size: medium

Education: high school

Education: college

$\begin{array}{lll}.111 & -.546 & .000 \\ .110 & -.318 & .004 \\ .110 & .266 & .016 \\ & & \\ .006 & -.017 & .005 \\ .188 & -.409 & .030 \\ .106 & -.256 & .015 \\ .134 & -.264 & .048 \\ .138 & -.529 & .000\end{array}$

\section{Copyrights}

Copyright for this article is retained by the author(s), with first publication rights granted to the journal.

This is an open-access article distributed under the terms and conditions of the Creative Commons Attribution license (http://creativecommons.org/licenses/by/4.0/). 